\title{
How to Promote the Flowing of Science and Technology Talents in Universities-Based on the Supply Side
}

\author{
Shanyou Yang, Long Cheng, Ye Wang \\ Exchange, Development \& Service Center for Science \&Technology Talents, The Ministry of Science \& Technology (MoST), \\ Beijing, China \\ Email: Chengl@sttc.net.cn
}

How to cite this paper: Yang, S.Y., Cheng, L. and Wang, Y. (2018) How to Promote the Flowing of Science and Technology Talents in Universities-Based on the Supply Side. Open Journal of Social Sciences, 6, 258-265.

https://doi.org/10.4236/jss.2018.611019

Received: October 30, 2018

Accepted: November 20, 2018

Published: November 23, 2018

Copyright $\odot 2018$ by authors and Scientific Research Publishing Inc. This work is licensed under the Creative Commons Attribution International License (CC BY 4.0).

http://creativecommons.org/licenses/by/4.0/

\begin{abstract}
The current situation and primary dilemma in the development of innovation and entrepreneurship talents flow faced by domestic universities are summarized in this research after field surveys and interviews at universities located in Beijing and Shanghai. It provides suggestions to promote the flow of innovative and entrepreneurial talents from the supply-side, which includes two modes and personnel management classification incentive systems, which can provide decision-making for the forward-looking and targeted work of enhancing the work of science, therefore accelerating the promotion of "mass entrepreneurship and innovation".
\end{abstract}

\section{Keywords}

Innovation and Entrepreneurship in Colleges and Universities, Supply-Side Reformation, Flow of Scientific and Technological Talents, Policy Research

\section{Research Background}

In recent years, innovative and entrepreneurial scientific and technological talents have increasingly emerged in colleges and universities, and positive progress has been achieved in the development of enterprises-universities-researches Integration. However, a number of prominent problems cannot be neglected referring to the inefficient flow of innovative and entrepreneurial talents between universities and enterprises and the imperfect policy service system. To solve these issues, it is urgent to fully understand the law of the flow and development of innovative and entrepreneurial talents in colleges and universities, learn advanced experience from foreign countries and strengthen policy guidance and 
support. We aim to build a flow mechanism for the innovation and entrepreneurship of science and technology talents in colleges and universities that can meet the requirements of "supply-side reformation" and "mass entrepreneurship and innovation" [1].

A certain number of cities in China have launched the policies and measures that encourage innovation and entrepreneurship talent flow in colleges and universities combining their own actual situations. For instance, Beijing, Shanghai and Tianjin have published the corresponding policy document with the comprehensive consideration of city orientation and development basis. Firstly, two-way flow of scientific research talents system is established. Shanghai announced the "Implementation Opinions on Deepening the Reform of Institutional Mechanism for Talent Development to Facilitate Innovation and Entrepreneurship", which proposes to complete the two-way flow of scientific research talents system and allows scientific research personnel to start up businesses at their post or after the demission [2] [3].

Secondly, these policies and measures provide a platform for the scientific and technical personnel to get involved in technology entrepreneurship and achievement transformation. Beijing launched the "Opinions on acceleration of technical achievement transformation and collaborative innovation in science and technology in colleges and universities" (or "Ten Items for Beijing Colleges and Universities") with three key purposes. First, it aims to strengthen innovation of technical achievement transformation system and mechanism in colleges and universities. Second, it is helpful to take maximum advantage of colleges and universities in the construction of capital innovation system and in the condition that they form the first innovation-driven development pattern. Third, it can effectively motivate their enthusiasm in the technical achievement transformation and collaborative innovation in science and technology. In this document, the idea that to encourage the technology entrepreneurship and achievement transformation in colleges and universities was clearly presented [4] [5].

Thirdly, these policies and measures explored the realization pathway of two-way flow of innovation and entrepreneurship talents. Tianjin announced "University Science and Technology Innovation Project" implementation opinions that propose the reformation of ways of innovation and entrepreneurship talents flow. It allows and encourage the scientific and technical personnel (including the scientific and technical personnel who also in the executive leadership position) in Tianjin to start business out of their jobs. Specifically, the identity and title of those personnel could be reserved for 3 years and the file and salary remains in the normal promotion system [6].

\section{State-of-the-Art and Main Problems of Innovation and Entrepreneurship Talents in Domestic Universities}

The field surveys and interviews were implemented in Beijing and Shanghai where have the highest performance in developing the innovation and entrepre- 
neurship in colleges and universities. We investigated the concepts, policies, and measurements of the talents flow in government departments and universities and analyzed the key of success and the accompanied issues.

\subsection{Common Points and Different Characteristics Found in Field Research}

\subsubsection{Commonality}

There are three common points in Beijing and Shanghai in terms of innovative and entrepreneurial talents flow. First, they adopt a variety of policies in encouraging teachers and researchers in the collages and universities to launch entrepreneurial activities with certain financial support which includes multiple economic cooperation modes like equity participation; secondly, the position of teachers and researchers can be retained within 3 - 6 years during the implementation of their innovation and entrepreneurship; thirdly, these activities were generally led by the municipal government with the cooperation from other related departments offering help to provides guarantees.

\subsubsection{The Characters of Beijing}

Taking Zhongguancun as the biggest platform, Beijing makes scientific and technological cooperation with Zhongguancun with the advantages of the huge number and high quality of colleges and universities, forming a gathering effect in this capital university group. Meanwhile, Beijing pays close attention to connect with the national innovation and entrepreneurship policies, such as complying with the national 2011 plan to formulate the 2011 collaborative innovation plan within Beijing, and to encourage teachers and researchers to participate in the science and technology collaborative innovation activities held by companies.

For example, during the period of incubating projects, Peking University Entrepreneurship Training Camp provides free entrepreneurship training and self-rental training camps training camps for innovation and entrepreneurship talents for facilitating the flow and development of innovation and entrepreneurship talents, and reducing the entrepreneurship cost. Besides, the alumni resources provided by the Beijing University Alumni Association for innovation and entrepreneurship talents are also very helpful measurements, which can be used for reference. Another example, according to the different stages of the project, Tsinghua University has created an X-lab laboratory focusing on incubation and an entrepreneur accelerator aiming to the project rudiments which needs further support. The former is a profit-making organization which can provide more financial support. While the latter is a non-profit organization, giving more support on training (similar to Peking University entrepreneurship training camp).

Both universities have encountered obstacles during the practice, which are either the unwillingness of college teachers due to the concepts solidification, or financing difficulties. This indicates that minds emancipation and concepts 
transformation is necessary. Meanwhile, the government should take the financing difficulties into full consideration when implementing corresponding supporting incentive policies, such as negotiate with banks to serve as the surety to ensure that the support funds for innovation and entrepreneurship projects arrive smoothly.

At the same time, teachers have patented technologies or associate professor titles have the strongest willingness to carry out innovation and entrepreneurship. In future practice of innovation and entrepreneurship, the government and colleges can focus on guiding these teachers in scientific and technological achievements transformation.

\subsubsection{The Characters of Shanghai}

Shanghai promotes the innovation and entrepreneurship to an internationalization level from an international perspective and attracts international talents at the same time. In the domestic, Shanghai proposes to use household registration to attract talents and break the predicament of retaining talent who have difficulties in settlement. Moreover, the colleges and universities in Shanghai respond quickly to the flow policies of science and technology talents in innovation and entrepreneurship issued by the state and municipal governments, and encourage teachers to implement innovation and entrepreneurship in light of their own situation.

For example, Fudan University and Shanghai Jiaotong University have also provided supportive policies to the innovation and entrepreneurship of talents in colleges and universities in accordance with the policies on innovation and entrepreneurship in Shanghai. A part of teachers have introduced the scientific and technological knowledge into the enterprises practice, transforming into productive forces. The "bring-in" idea proposed by Fudan University is of great significance to attracting off-campus talents, especially the international excellent enterprise talents. For Shanghai Jiaotong University, it sets a "non-natural flow rate" policy which is an innovative experiment to promote the talents flow without preconceived obstructions, promoting the flow of scientific and technological talents. However, these two universities have not made any specific implementation rules for the innovation and entrepreneurship of teachers. This reflects that the responses are still slightly lagging behind to the new phenomenon of innovation and entrepreneurship of teachers in colleges and universities which need the guidance from the government to gradually complete the implementation rules.

\section{Problems in Innovation and Entrepreneurship Technical Talents Flow in Domestic Universities}

1) Talent system. At present, only first-tier cities such as Beijing, Shanghai, Guangzhou, and Shenzhen have clear policy support pointing at the innovative and entrepreneurial technology talents flow. The corresponding talent system is significantly falling behind in most of other cities limited by local concept solidi- 
fication and policy restrictions in spite of the strong willingness in attracting university talents to start their own businesses and further drive economic development. Although the cities have already formulated corresponding policies and implementation measures, it is still unknown whether various policies and measures can be fully implemented and innovative and entrepreneurial activities can be strongly supported due to involvement of multiple stakeholders.

2) The impact on the organizational ecology of University. Universities in China are non-profit educational units, which are directly managed or supervised by the education authorities. The organizational forms of universities, especially public universities, are relatively inflexible. This kind of organizational status cannot be changed in a short period of time, so the university talents will have numerous inside and outside system considerations when they operate business. Meanwhile, a proportion of existing organizational ecology does not fully encourage university teachers in the system to go out for innovation and entrepreneurship, which will affect the promotion and implementation of innovation and entrepreneurship measures.

3) Evaluation and incentive systems. From the experience of the existing areas where the evaluation and incentive system has been formulated, the incentives are gradually increasing and the supporting funds are also abundant, but the corresponding performance evaluation mechanism is still imperfect. What kind of work is done by innovative and entrepreneurial talents, there is still short of scientific evaluation indicators about the assessment of types of work and achievement to get the stimulation and financial support.

\section{Policy Suggestions on Innovation and Entrepreneurship of Scientific and Technological Talents Flow in Colleges and Universities}

To promote innovation and entrepreneurship of scientific and technological talents flow in Chinese universities, we have to learn successful experience from foreign countries. At the same time we need to design scientific and rational models, processes as well as rules after combining the development stage of domestic universities and the actual situation of government departments.

\subsection{Two Processes: "Incubation-Exploration-Establishment" and "Short Lecture-Systematic Teaching-Formal Part-Time"}

The cultivation and flow management of innovative talents in colleges and universities needs to pay attention to two processes, namely "incubation-exploration-establishment" and "short lecture-systematic teaching-formal part-time". The former focuses on the development of innovation and entrepreneurial achievements and the construction of innovation platforms, while the latter focuses more on the cultivation of innovative talents.

First, we need to pay special attention to the whole process of "incubation-exploration-establishment", so as to promote the output of innovation and entrepreneurship and sustainable development. We need to establish a high- 
level independent innovation and entrepreneurship platform relying on multidimensional carriers, which can provide more resources for the cultivation of innovative, entrepreneurial scientific and technological talents and the transformation of innovative achievements. The process of building an innovative business incubator base is a continuously exploring process. In the process of operation, we should improve the function of the comprehensive service platform for innovation and entrepreneurship, and realize policy consultation, project recommendation, talent introduction, financing services, exchange guidance, etc., and finally establish a sound system platform. In other words, the emphasis on the process of "incubation-exploration-establishment" is not only about the final result of knowledge transformation, but also constantly self-renewing in the process of providing services and promoting the self-improvement of the platform in the dynamic. Meanwhile, this process is also a practice and experience accumulation for innovative entrepreneurs themselves.

Secondly, we should gradually introduce diversified innovation talents through two aspects: invite off-campus innovation and entrepreneurship research talents and practical talents in the "short lectures-systematic teaching-formal part-time" process; invite experts to give lectures to exchange experience and hire them as innovative and entrepreneurial tutor and other means. In the general environment of internet popularization, we should also build a resource platform that the network and the entity can use cooperatively, realize the sharing of innovative knowledge and experience in all aspects, meet the requirements of the construction of innovative talents group, and improve the innovation ability and the transformation rate of innovation ability.

\subsection{Personnel Management Classification Incentive System}

Incentives are the core of management work which needs diversity to satisfy different preferences of talents. Only effective incentives for innovative and entrepreneurial talents in universities can accelerate their rational mobility. This kind of incentive can be embodied in various management systems and differentiated incentive systems should be established for different types of talents. According to the characteristics of personnel, talents in colleges and universities can be divided into scientific innovation talents, technological innovation talents and management innovation talents, requiring diverse performance evaluations and career channels. Therefore, classified management system should be developed for innovation and entrepreneur personnel.

\subsubsection{Research Innovation Talents and Technological Innovation Talents}

In terms of performance assessment, it should not be limited to the rigidity index such as the number of publications, the level of issued journals etc., but also needs to introduce interdisciplinary research assessment, or new product development, new technology innovation and popularization of practical results cooperated with enterprises. Colleges and universities should guide the talent man- 
agement corresponding with new knowledge production methods to fully motivate outstanding talents who have interdisciplinary knowledge systems and innovative knowledge applications. Therefore, in the performance evaluation, such comprehensive indicators should be introduced to guide scientific research and technical workers towards innovation.

For career channels, colleges and universities should build up outreach promotion mechanisms and provide sufficient research funding so that innovative talents can concentrate on innovative research and development [7]. This will not only encourage existing innovative talents, but also give full play to the exemplary role of typical character and drive more outstanding scientific and technological innovation talents. At the same time, sufficient financial support can provide necessary material support for scientific and technological innovation work, avoid divergence of energy, and keep the long-time vigor of research and innovation.

\subsubsection{Managerial Innovation Talents}

Referring to performance assessment, for the managerial innovative talents, assessment of performance should not be only limited to the routine management work. In order to mobilize their innovative enthusiasm, additional scores should also be added for the innovative suggestions of management work, innovative system design and implementation item. These assessment indicators can effectively stimulate the managerial innovative talents, which is of great significance for promoting the construction and development of innovation and entrepreneurship in colleges and universities.

In terms of career channels, combining the characteristics that innovation entrepreneurship requires multiple participants, universities need to maintain good interaction with the government and enterprises. Therefore, managerial innovation talents should also be promoted in the management of colleges and universities, or move to management positions like cooperative enterprises, parks, government high-tech zones, social organizations to open up multiple career path. From this point, managerial innovation talents can be encouraged to introduce more resources needed for entrepreneurial ecology and to play a connecting role among colleges and universities, governments and enterprises. At the same time, they can also introduce the advanced management concepts and methods of other organizations into the management of colleges and universities, and promote the innovation and development of colleges and universities.

In short, starting from the supply side, based on the characteristics of the development of innovative and entrepreneurial technology talents flow, we can sum up the international science and technology talent mobility policies and experience, and analyze the new trends, new models and new mechanisms involving science and technology talents who participate in innovation and entrepreneurship. These summaries and analysis can not only provide the path and countermeasures for the government to promote the innovation and entrepreneurship of science and technology talents, further supply directions and sugges- 
tions for the subsequent policy release, but also provide decision-making reference in the course of promoting "mass entrepreneurship and innovation".

\section{Conflicts of Interest}

The authors declare no conflicts of interest regarding the publication of this paper.

\section{References}

[1] Liu, Y.D. (2015) Deepening the Reform of Innovation and Entrepreneurship Education, and Fostering a Highly Innovative Entrepreneurial Force. Symposium on Deepening the Reform of Innovation and Entrepreneurship Education in Colleges and Universities. China Education Daily, 2015-10-26.

[2] Hall, K. (2011) University Research Centers: Heuristic Categories, Issues, and Administrative Strategies. Journal of Research Administration, 42, 25-41.

[3] Sun, X.K. (2014) American Science and Technology Talent Strategy and Its Enlightenment to China. Journal of Nanjing University of Posts and Telecommunications (Social Sciences Edition), 16, 112-118.

[4] Qu, X.L. (2016) Analysis the Talents Policy in the Context of Encouraging Mass Entrepreneurship and Innovation. Science and Technology Management Research, 17, 41-45.

[5] Chen, J.X., Chen, J. and Liu, Z.J. (2018) The Latest Policy Analysis of Innovative Talents at Home and Abroad and It's Enlightenment to Guangdong. Science and Technology Management Research, 15, 59-67.

[6] Rindoks, A. (2010) The International Mobility of Talent: Types, Causes and Development Impact. Journal of Ethnic and Migration Studies, 36, 709-710.

[7] Fang, J.Q. and Lu, S.J. (2014) Analysis of the Characteristics and Differences of Entrepreneurship Education in American and Japanese Universities. Higher Education Exploration, 5, 101-105. 